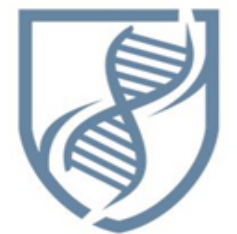

Journal of Bioscience and Applied Research

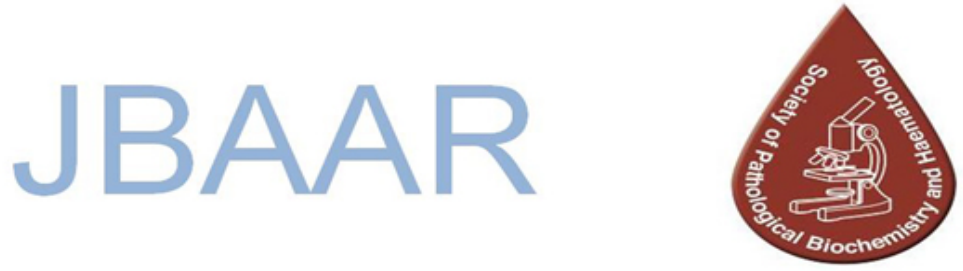

WWW.JBAAR.ORG

\title{
Study the association between glutathione peroxidase-1 gene in patients with hepatocellular carcinoma in Egypt
}

\author{
Ibrahim A. Elelaimy ${ }^{1}$, Eman L. Shehata ${ }^{2}$, Mohamed A. Abdel-Hamid ${ }^{3}$ \\ 1 Zoology Department, Faculty of Science, Menoufia University \\ 2 National liver institute, Menoufia University \\ 3 Microbiology Department, Faculty of Medicine, Minia University \\ Corresponding author e.mail. emanlabib2009@hotmail.com
}

\section{Abstract}

cancer in the world. The main risk factors associated with HCC are hepatitis B and hepatitis C viral infections and other factors that play a role in HCC development. Oxidative stress is an imbalance between production and elimination of reactive metabolites of oxygen and nitrogen, in favor of their production leading to potential damage. During oxidative stress, biologically important molecules and cells can be damaged, and this can be significant in the pathogenesis of many diseases. Reactive oxygen species (ROS) is known to activate the apoptosis of some hepatocytes and therefore contribute to inflammation, regeneration, fibrogenesis, and carcinogenesis. The enzyme generally considered to be the frontline defense against ROS is glutathione peroxidase (GPX).The present study aims to investigate the association of progression of HCC with GPX1 (Pro198Leu) gene polymorphisms in HCC Egyptian patients. One hundred HCC cases and matched 100 controls were recruited from National Cancer Institute and Kasr El-Aini respectively. The detection of the genetic polymorphisms of GPX1 (Pro198Leu) were determined by single nucleotide polymorphisms (SNPs) using real time PCR technique. The results showed that there is a significant association between the GPX1 polymorphisms and the progression of HCC, the distribution of different GPX1 polymorphisms in HCC patients infected with HCV was (47.5\% CC, 47.0\% CT and $81.3 \% \mathrm{TT})$ respectively and in controls was $(52.5 \%$ CC, $53.0 \% \mathrm{CT}$ and $18.8 \% \mathrm{TT}$ ) respectively $(P=0.033)$. Our findings suggested that the genetic polymorphisms in GPX1 play a role in the etiology of hepatocellular
\end{abstract}

carcinoma.Conclusion: AFP is highly significant in relation to HCC cases and in also with GPX1 gene mutation. Our findings suggested that the genetic polymorphisms in GPX1 play a role in the etiology of hepatocellular carcinoma.

Keywords: Hepatocellular carcinoma, glutathione peroxidase gene, gene polymorphisms, Egyptian patients

\section{Introduction}

Hepatocellular carcinoma (HCC) is a major source of cancer burden worldwide, and is the third leading cause of cancer-related mortality (Zhou et al., 2013). Incidence varies widely between geographical areas, probably because of variations in the exposure to hepatitis virus and other environmental pathogens (ElSerag, 2001). In Egypt, HCC is the second most common cancers in men and the $6^{\text {th }}$ most common cancers in women (GLOBOCAN 2008 database). As with many cancers, variants of genes involved in multistage carcinogenesis may determine an individual's susceptibility to develop HCC. Single nucleotide polymorphisms (SNPs) are the most common type of genomic sequence variation and are thought to be associated with population diversity, susceptibility to disease, and individual response to drug treatment (Shastry, 2002).

The clinical risk factors include cirrhosis, Chronic Hepatitis C Virus (HCV) Infection, Chronic Hepatitis B Virus (HBV) Infection, Co- Infection of HBV and HCV Virus, Schistosomiasis, aflatoxin B1 (AFB1), 
and alcoholism. The environmental risk factors include the pesticides and Cigarette Smoking (Anwar et al., 2008).

HCV infection causes liver inflammation and variable grade of damage to the organ that over decades can lead to cirrhosis (Ikeda et al., 1993; Tsukuma et al., 1993; Lauer and Walker, 2001). Egypt has one of the highest prevalence rates of $\mathrm{HCV}$ infection. Disease progression is influenced by additional factors such as duration of infection, age at infection, gender, coinfection with HBV, and the level of HCV viramia and its genotype (Anwar et al., 2008).

Free radicals that contain the element oxygen are the most common type of free radicals produced in living tissue. Another name for them is "Reactive Oxygen Species" or "ROS". Antioxidants are chemicals that interact with and neutralize free radicals, thus preventing them from causing damage. Antioxidants are also known as "free radical scavengers" (Diplock et al., 1998; Bouayed and Bohn, 2010; Poli et al., 2004). Glutathione peroxidase (GPX1) is an antioxidant enzyme that protects the organisms from oxidative damage (Chandrasena et al., 2006).

Glutathione Peroxidase (GPX) catalyzes the reduction of $\mathrm{H} 2 \mathrm{O} 2$ or organic hydroperoxides to water or the corresponding alcohols using reduced glutathione. The mammalian GPX family is divided into six clades according to their amino-acid sequence, substrate specificity and sub-cellular localization: classical or cytosolic (GPX1), the first mammalian GPX to be identified; gastrointestinal (GPX2); plasma (GPX3); phospholipid hydroperoxide (PHGPX or GPX4); epididymal (GPX5); olfactory epithelium (GPX6) (Mills, 1957; Flohe et al., 1973; Rotruck et al., 1973).

GPX-1 Mills first described GPX activity in 1957 (Mills, 1957), and its function was hypothesized to be protection of red blood cells against hemolysis by oxidation (Bhabak and Mugesh, 2010). Activity levels of the antioxidant enzyme GPX1 is likely affected by functional polymorphisms in the genes encoding them. A polymorphism in the GPX1 gene (Pro198Leu), encoding the isoenzyme GPX1, was reported to have a relation to HCC development (Sutton et al. 2006).

The genetic polymorphism of glutathione peroxidase-1 may have a significant effect on the enzyme activity. In particular, polymorphism in GPX1 Pro198Leu $(\mathrm{C} \rightarrow \mathrm{T})$ located in the second exon of gene GPX1 has a high level of heterozygosity; it induces a proline (CCC)-leucine (CTC) substitution. Moreover, it may have an effect on the catalytic enzyme activity, its affinity to the substrate, specificity, structure stability, etc (Zheikova, 2012). With the use of cell lines, it was shown that Pro198Leu enzyme had lower activity compared to wild type protein. Catalytic gene activity was found to be $5 \%$ lower in each additional $\mathrm{T}$ copy in patients with this allele (Ravn_Haren et al., 2006).

Genetic variations in the antioxidant gene coding for the GPX1 enzyme may cause decreased or impaired regulation of their enzymatic activity and alter ROS detoxification. Therefore, genetic variations among these enzymes that protect the cell against ROS may lead to disease (Forsberg et al., 2001). Due to the high interaction potentiality of ROS with genetic material, polymorphisms in genes coding for antioxidant enzymes may play an important role for inter-individual differences in maintaining the human genome's integrity. Genetic polymorphisms in GPX1 have been implicated in proneness to cancer and other diseases (Tang et al., 2010; Cebrian et al., 2006). The present study aims to investigate the association of progression of HCC with GPX1 (Pro198Leu) gene polymorphisms in HCC Egyptian patients.

\section{Materials and methods Sample Collection:}

This study is a case-control study. It was conducted on a total number of 200 individuals divided into two groups, Group I included 100 HCC cases and group II included 100 healthy subjects recruited from National Cancer Institute and Kasr Al-Aini hospital respectively. Ten $\mathrm{ml}$ of blood withdrawn from cases and controls in EDTA tubes under complete aseptic condition. All samples were centrifuged, plasma and Buffy coat separated, aliquated and stored at $-80^{\circ} \mathrm{C}$. Buffy coat used for detection of polymorphism of GPX1 gene and plasma used for HCV PCR testing and determination of AFP.

\section{Methods:}

All HCC cases and controls included in this study were subjected to the Alphafeto Protein (AFP) using AxSYM AFP (Abbott Laboratories, USA, Diagnostics Division), HCV PCR by Reverse Transcriptase-Polymerase Chain Reaction (RT-PCR) and detection of GPX1 gene polymorphism by real time PCR.

\section{HCV RT-PCR}

HCV RNA RT-PCR was performed in a total volume of $100 \mu \mathrm{l}$ containing $1 \mathrm{X}$ Taq buffer with $1.5 \mathrm{mM}$ $\mathrm{MgCl}_{2}$ (Roche Molecular Biochemicals, Mannheium, Germany), 0.2mM dNTPs (Promega Madison, WI, USA), 20 pmole of each primers (P1 and P2), 20 units of Human Placental Ribonuclease Inhibitor (HPRI) (RNasin) (Promega Madison, WI, USA), 10 units of AMV Reverse Transcriptase (RT) (Promega Madison, WI, USA), and 2.5 units Taq DNA polymerase (Roche Molecular Biochemicals, Mannheium, Germany). A 90 $\mu$ l of master mix was added to each sample and the mixture was incubated at $42^{\circ} \mathrm{C}$ for $30 \mathrm{~min}$ for RT (one cycle), $95^{\circ} \mathrm{C}$ for 4 min (one cycle), followed immediately by 35 cycles of the following conditions: $94^{\circ} \mathrm{C}$ for 1 minute, $50^{\circ} \mathrm{C}$ for 1 minute and $72^{\circ} \mathrm{C}$ for 1 minute. A final cycle of $72^{\circ} \mathrm{C}$ for 10 minutes at the GeneAmp PCR Systems 9600 (Applied Biosystems). Nested PCR was performed by the transfer of $10 \mu \mathrm{l}$ of the first PCR product to $90 \mu \mathrm{l}$ of the second master mix containing $1 \mathrm{X}$ Taq buffer (Roche Diagnostics), 0.2mM dNTP's (Promega), 20 pmole of each nested primer (P3 and P4), 2.5 units Taq polymerase (Roche Diagnostics). The samples were incubated for 35 cycles as in step 2 without the initial RT step. Finally, 
PCR results were visualized by electrophoresis on ethidium bromide stained 3\% agarose gel in 0.5X TBE buffer (GIBCO-BRL, Life Technologies, Gaithersburg, MD, USA). The primers were derived from the highly conserved 5'-untranslated region (5'UTR) of HCV genome (Abdel-Hamid et al., 1997).

\section{Detection of GPX1 gene polymorphism by Real time PCR technique:}

DNA was extracted from Buffy Coat samples by using QIAamp DNA Mini Kit (Qiagen, Santa Clarita, USA). The polymorphism for GPX1 (rs1050450) was genotyped by real-time PCR fluorescence detection on an ABI PRISM $® 7500$ Real Time PCR System (Applied Biosystems, USA) using fluorescent labeled probes. Each $15 \mu$ PCR reaction contained 20 pmol of forward primer 5'-CATCGAAGCCCTGCTGTCT-3', 20 pmol of reverse primer 5'-CACTGCAACTGCCAAGCA-3', 5 pmol of fluorescent oligonucleotide probes 5'-(FAM)ACAGCTGAGCCCTT-(MGB)-3', 5 pmol of fluorescent oligonucleotide probe 5'-(VIC)- ACAGCTGGGCCCTT(MGB)-3', $7.5 \mu$ l of 2X TaqMan Universal PCR Master Mix (Applied Biosystems) and 2 ng DNA. The PCR cycling conditions consisted of: 2 min cycle at $50^{\circ} \mathrm{C}$ and 10 min cycle at $95^{\circ} \mathrm{C}$, followed by 49 cycles of $95^{\circ} \mathrm{C}$ for $30 \mathrm{~s}$ and $60^{\circ} \mathrm{C}$ for $1 \mathrm{~min}$. Distilled water was used as a negative PCR control in each amplification.

\section{Results}

Table 1 shows that the HCC GPX1 cases had AFP ranged 354.58 \pm 449.6 for CC genotype, $733.77 \pm 463.9$ for CT genotype and $872.16 \pm 385.6$ for TT genotype which is a highly significant $(P<0.0001)$ and the controls for GPX1 had AFP ranged 3.37 \pm 2.4 for CC genotype, 3.03 \pm 2.27 for CT genotype and 2.22 \pm .26 for TT genotype which is not significant $(P=0.606)$.

Table 2 shows that Among HCC cases; the HCV antibodies (HCV Ab) were positive in 43(89.6\%) of GPX1 (CC genotype) and negative in 5(10.4\%) of CC genotype. HCV Ab were positive in $34(87.2 \%)$ of $\mathrm{CT}$ genotype and negative in $5(12.8 \%)$ of CT genotype. HCV $\mathrm{Ab}$ were positive in 12(92.3\%) of TT genotype and negative in $1(7.7 \%)$ of TT genotype, which is not significant $(p=0.863)$.

Among HCC cases; the HCV PCR were positive in 39(81.3\%) of GPX1 (CC genotype) and negative in $9(18.8 \%)$ of CC genotype. HCV PCR were positive in $32(82.1 \%)$ of CT genotype and negative in 7(17.9\%) of CT genotype, while HCV PCR were positive in $11(84.6 \%)$ of TT genotype and negative in $2(15.4 \%)$ of
TT genotype, which is not significant ( $p=0.961)$. Among controls; $\mathrm{HCV}$ antibodies (HCV Ab) were positive in $22(41.5 \%)$ of GPX1 (CC genotype) and negative in $31(58.5 \%)$ of CC genotype. HCV Ab were positive in $18(40.9 \%)$ of CT genotype and negative in $26(59.1 \%)$ of CT genotype. HCV Ab were positive in 1(33.3\%) of TT genotype and negative in $2(66.7 \%)$ of $\mathrm{TT}$ genotype, which is not significant $(P=0.961)$.

Among controls; HCV PCR were positive in $14(26.4 \%)$ of GPX1 (CC genotype) and negative in $39(73.6 \%)$ of CC genotype. HCV PCR were positive in $11(25.0 \%)$ of CT genotype and negative in 33(75.0\%) of CT genotype, while HCV PCR were negative in all TT genotype $3(100 \%)$, which is not significant $(P=0.590)$.

Table 3 shows that regarding to the HCC cases; GPX1 (CC polymorphism) was found in $48(48 \%)$ of the HCC cases, while it was found in 53(53\%) of the controls; CT polymorphism was found in 39(39\%) of HCC cases while it was found in 44(44\%) of the controls; TT polymorphism was found in $13(13 \%)$ of HCC cases while it was found in $3(3 \%)$ of the controls, which is significant $(P=0.033)$.

Regarding to the HCC cases; the functioning GPX1 (CC+CT polymorphisms) were found in $87(87 \%)$ of HCC cases while they were found in $97(97 \%)$ in the controls. The Malfunction GPX1 (TT polymorphism) was found in $13(13 \%)$ of HCC cases while it was found in $3(3 \%)$ in the controls, which is significant $(P=0.009)$.

\section{Discussion}

Our work was conducted to detect the association between glutathione peroxidase 1 (GPX1) gene in patients with Hepatocellular Carcinoma in Egypt.

Glutathione peroxidase-1, a selenium dependent enzyme, and the proline-leucine substitution makes it less sensitive to stimulation by the addition of selenium (Hu and Diamond, 2003). Several research groups have revealed the association between the polymorphism and various diseases caused by the oxidative stress (breast cancer, lung cancer, leukosis, metabolic syndrome, CAD) (Tang et al., 2008, Ravn_Haren et al., 2006, Cox et al., 2006).

In this study, we found a significant association between the GPX1 polymorphism and the progression of HCC, the distribution of different GPX1 polymorphisms in HCC patients infected with HCV was (48.0\% CC, 39.0\% CT and $13.0 \% \mathrm{TT})$ respectively and in controls was $(53.0 \%$ CC, $44.0 \%$ CT and $3.0 \% \mathrm{TT})$ respectively $(P=0.033)$. 
Table.1 The mean and SD of AFP in HCC GPX1 patients and controls

\begin{tabular}{|c|c|c|c|c|c|c|c|c|c|c|}
\hline & $\begin{array}{l}\mathrm{HCC} \\
\mathrm{GPX} 1\end{array}$ & $\begin{array}{c}\text { N/Total } \\
(\%)\end{array}$ & Mean & SD & $P$ value & Controls & $\begin{array}{c}\text { N/Total } \\
(\%)\end{array}$ & Mean & SD & $\begin{array}{c}P \\
\text { value }\end{array}$ \\
\hline \multirow{3}{*}{ AFP } & $\mathrm{CC}$ & $48(48 \%)$ & 354.58 & 449.6 & \multirow{3}{*}{$<0.0001$} & $\mathrm{CC}$ & $53(53 \%)$ & 3.37 & 2.4 & \multirow{3}{*}{0.606} \\
\hline & $\mathrm{CT}$ & $39(39 \%)$ & 733.77 & 463.9 & & $\mathrm{CT}$ & $44(44 \%)$ & 3.03 & 2.27 & \\
\hline & $\mathrm{TT}$ & $13(13 \%)$ & 872.16 & 385.6 & & TT & $3.0(3 \%)$ & 2.22 & 26 & \\
\hline
\end{tabular}

Table.2 HCV Ab and HCV PCR in HCC GPX1 patients and controls

\begin{tabular}{|c|c|c|c|c|c|c|c|c|c|c|}
\hline & $\begin{array}{l}\mathrm{HCC} \\
\text { GPX1 }\end{array}$ & $\begin{array}{c}\text { N/Total } \\
(\%)\end{array}$ & Positive & Negative & $P$ value & Controls & $\begin{array}{c}\text { N/Total } \\
(\%)\end{array}$ & Positive & Negative & $\begin{array}{c}P \\
\text { value }\end{array}$ \\
\hline \multirow{3}{*}{$\begin{array}{l}\mathrm{HCV} \\
\mathrm{Ab}\end{array}$} & $\mathrm{CC}$ & $48(48 \%)$ & $43(89.6 \%)$ & $5(10.4 \%)$ & \multirow{3}{*}{0.863} & $\mathrm{CC}$ & $53(53 \%)$ & $22(41.5 \%)$ & $31(58.5 \%)$ & \multirow{3}{*}{0.961} \\
\hline & $\mathrm{CT}$ & $39(39 \%)$ & $34(87.2 \%)$ & $5(12.8 \%)$ & & $\mathrm{CT}$ & $44(44 \%)$ & $18(40.9 \%)$ & $26(59.1 \%)$ & \\
\hline & $\mathrm{TT}$ & $13(13 \%)$ & $12(92.3 \%)$ & $1(7.7 \%)$ & & $\mathrm{TT}$ & $3.0(3 \%)$ & $1(33.3 \%)$ & $2(66.7 \%)$ & \\
\hline \multirow{3}{*}{$\begin{array}{l}\mathrm{HCV} \\
\mathrm{PCR}\end{array}$} & $\mathrm{CC}$ & $48(48 \%)$ & 39(81.3\%) & $9(18.8 \%)$ & \multirow{3}{*}{0.961} & $\mathrm{CC}$ & $53(53 \%)$ & $14(26.4 \%)$ & $39(73.6 \%)$ & \multirow{3}{*}{0.590} \\
\hline & $\mathrm{CT}$ & $39(39 \%)$ & $32(82.1 \%)$ & $7(17.9 \%)$ & & $\mathrm{CT}$ & $44(44 \%)$ & $11(25.0 \%)$ & $33(75.0 \%)$ & \\
\hline & $\mathrm{TT}$ & $13(13 \%)$ & $11(84.6 \%)$ & $2(15.4 \%)$ & & $\mathrm{TT}$ & $3.0(3 \%)$ & 0 & $3(100 \%)$ & \\
\hline
\end{tabular}

Table.3 Polymorphism and functioning GPX1

\begin{tabular}{|c|c|c|c|c|c|c|c|c|c|}
\hline \multirow{4}{*}{ GPX1 } & $\mathrm{HCC}$ & $\begin{array}{c}\text { N/Total } \\
(\%)\end{array}$ & Controls & $\begin{array}{c}\text { N/Total } \\
(\%)\end{array}$ & $P$ value & GPX1 & $\mathrm{HCC}$ & Controls & $P$ value \\
\hline & $\mathrm{CC}$ & $48(48 \%)$ & $\mathrm{CC}$ & $53(53 \%)$ & \multirow{3}{*}{0.033} & $\begin{array}{l}\text { Functioning } \\
\qquad(\mathrm{CC}+\mathrm{CT})\end{array}$ & $87(87 \%)$ & $97(97 \%)$ & \multirow{3}{*}{0.009} \\
\hline & $\mathrm{CT}$ & $39(39 \%)$ & $\mathrm{CT}$ & $44(44 \%)$ & & \multirow{2}{*}{$\begin{array}{l}\text { Malfunction } \\
\text { (TT) }\end{array}$} & \multirow{2}{*}{$13(13.0 \%)$} & \multirow{2}{*}{$3(3.0 \%)$} & \\
\hline & $\mathrm{TT}$ & $13(13 \%)$ & $\mathrm{TT}$ & $3.0(3 \%)$ & & & & & \\
\hline
\end{tabular}

In agreement to our study, Ravn-Haren et al., resulting from HCV infection and passes through liver 2006 found that erythrocyte GPX1 activity was lower in cirrhosis to the development of HCC. Although none of individuals carrying the Leu allele than in individuals their participants had Leu/Leu genotype, our allelic results carrying the Pro allele. Genetic variant in GPX1 gene suggest that this genotype might possess the highest risk in polymorphism that increases cancer risk may also cause this process.

alteration in the activity of the enzyme and hence alteration

Another study with Nahon and co-outers 2012 in the oxidant-antioxidant balances. Thus, the less active (Nahon et al., 2012) Nahon et al., 2012 who carried out Leu-GPX1 variant may increase the risk of bladder cancer study on HCV-induced cirrhosis patients and followed due to decreased protection against ROS-induced oxidative them up for HCC development, it was found that patients damage. with HCC had a frequency of Pro/Pro genotype (29.4\%),

Another study done by Abd El-Ghaffar et al., Pro/Leu genotype (38.7\%), and Leu/Leu genotype (45\%). (2015) who found that GPX1 gene polymorphism They stated that patients bearing two Leu-GPX alleles had individuals bearing Leu allele had a 4.915-fold when higher rates of death.

comparing the HCC group to the control subjects

Our results were supported by the results of Sutton $(P=0.001)$. These results suggested that Pro/Leu genotype et al., 2006 who found that Leu GPX allele bearing patients might be risky for the development of the inflammation had a higher incidence of HCC during follow-up of 
alcohol-induced cirrhotic patients. They explained that by the slow detoxification of hydrogen peroxide by the low activity-associated Leu-GPX variant.

However, in a study was done by Ezzikouri et al., 2010 and found no statistical difference in GPX1 genotypic frequency between HCC and control groups $(P=0.685)$.

With regard to GPX1 (Pro 198 Leu) gene, our study showed a statistically significant difference on comparing AFP between GPX1 genotypes (Pro/Pro, Pro/Leu, Leu/Leu) among HCC patients. The median of AFP were $(354.58 \pm 449.6), \quad(733.77 \pm 463.9) \quad$ and (872.16 \pm 385.6$)$ respectively $(P<0.0001)$.

In accordance with our results, a study by Abd ElGhaffar et al., 2015 found a statistically significant difference on comparing AFP between GPX1 genotypes (Pro/Pro, Pro/Leu) among HCC patients $(P=0.004)$.

\section{References}

Abd El-Ghaffar HA, Ahmed AI, Abdelaal AA. Emam RF, Mansour LA. (2015). Antioxidant enzymes gene polymorphisms and hepatocellular carcinoma in hepatitis $\mathrm{C}$ virus-infected Egyptian patients. Comp Clin Pathol , 24(3): 609-615.

Abdel-Hamid M, Edelman DC, Highsmith WE, Constantine NT. (1997).Optimization, assessment, and proposed use of a direct nested reverse transcriptionpolymerase chain reaction protocol for the detection of hepatitis C virus. J Hum Virol; 1: 58-65.

Anwar WA, Khaled HM, Amra HA, (2008).Changing pattern of hepatocellular carcinoma (HCC) and its risk factors in Egypt: possibilities for prevention. Mutat Res , 659: 176-184.

Bhabak KP, Mugesh G. (2010). Functional mimics of glutathione peroxidase: bioinspired synthetic antioxidants. Acc Chem Res;, 43(11): 1408-1419.

Bouayed J, Bohn T.(2010). Exogenous antioxidants-double-edged swords in cellular redoc state: health beneficial effects at physiologic doses versus deleterious effects at high doses. Oxidative Medicine and Cellular Longevity, 3(4): 228-237.

Cebrian A, Pharoah PD, Ahmed S, Smith PL, Luccarini C, Luben R, Redman K, Munday H, Easton DF, Dunning AM, Ponder BA.(2006). Tagging singlenucleotide polymorphisms in antioxidant defense enzymes and susceptibility to breast cancer. Cancer Res , 66: 1225-1233.

Chandrasena LG, Chackrewarthy S, Perera PT, Silva D.(2006). Erythrocyte antioxidant enzymes in patients with cataract. Ann Clin Lab Sci , 36: 201-204.

Cox DG, Tamimi RM, Hunter DJ.(2006). Genegene interaction between MnSOD and GPX1 and breast cancer risk: A nested case control study. BMC Cancer , 6: 217.

Diplock AT, Charleux JL, Crozier-Willi G, (1998).Functional food science and defence against reactive oxygen species. British Journal of Nutrition , 80(Suppl 1): S77-S112.

El-Serag HB.(2001). Epidemiology of hepatocellular carcinoma. Clin Liver Dis , 5: 87-107.
Ezzikouri S, El Feydi AE, Afifi R, Benazzouz M, Hassan M, Pineau P, Benjelloun S.(2010). Polymorphisms in antioxidant defense genes and susceptibility to hepatocellular carcinoma in a Moroccan population. Free Radic Res ,44(2): 208-216

Flohe' L, Gunzler WA, Schock HH.(1973). Glutathione peroxidase: a selenoenzyme. FEBS Lett , 32: 132-134.

Forsberg L, Lyrenas L, Faire U, Morgenstern R. A.(2001). common functional C-T substitution polymorphism in the promoter region of the human catalase gene influences transcription factor binding, receptor gene transcription and is correlated to blood catalase levels. Free Radic Biol Med , 30(5): 500-505.

Cox DG, Tamimi RM, Hunter DJ.(2006). Genegene interaction between MnSOD and GPX1 and breast cancer risk: A nested case control study. BMC Cancer , 6: 217.

Hu YJ, Diamond AM.(2003). Role of glutathione peroxidase 1 in breast cancer: loss of heterozygosity and allelic differences in the response to selenium. Cancer Res ,63: 3347-3351.

Ikeda K, Saitoh S, Koida I. (1993).A multivariate analysis of risk factors for hepatocellular carcinogenesis: a prospective observation of 795 patients with viral and alcoholic cirrhosis. Hepatology , 18: 47-53.

Lauer GM, Walker BD.(2001).. Hepatitis C virus infection. N. Engl. J. Me , 345: 41-52.

Mills GC.(1957). Hemoglobin catabolism. Glutathione peroxidase, an erythrocyte enzyme which protects hemoglobin from oxidative breakdown. J Biol Chem , 266: 20752-20760.

Nahon $P$, Sutton A, Rufat P, Charnaux N, Mansouri A, Moreau R, Carrié NG, Lemaire VG, Kontchou GN, Trinchet JC, Pessayre D, Beaugrand M. (2012). A variant in myeloperoxidase promoter hastens the emergence of hepatocellular carcinoma in patients with HCV-related cirrhosis. Hepatology , 56: 426-432.

Poli G, Leonarduzzi G, Biasi F, Chiarpotto E. (2004).Oxidative stress and cell signaling. Curr. Med. Chem , 11: 1163-1182.

Ravn_Haren G, Olsen A, Tjonneland A, Dragsted LO, Nexo BA,(2006). Associations between GPX1 Pro198Leu polymorphism, erythrocyte GPX activity, alcohol consumption and breast cancer risk in a prospective cohort study. Carcinogenesis , 27: 820-825.

Rotruck JT, Pope AL, Ganther HE, Swanson AB, Hafeman DG, Hoekstra WG. (1973).Selenium: biochemical role as a component of glutathione peroxidase. Science, 179: 588-590.

Shastry BS.(2002). SNP alleles in human disease and evolution. J Hum Genet , 47: 561-566.

Sutton A, Nahon P, Pessayre D, Rufat P, Poire A, Ziol M.(2006). Genetic polymorphisms in antioxidant enzymes modulate hepatic iron accumulation and hepatocellular carcinoma development in patients with alcohol-induced cirrhosis. Cancer Res , 66(5): 2844-2852.

Tang NP, Wang LS, Yang L, Gu HJ, Sun QM.(2008).. Genetic variant in glutathione peroxidase 1 
gene is associated with an increased risk of coronary artery disease in a Chinese population. Clin. Chim. Acta , 395: 89-93.

Tang $\mathrm{H}$, Dong $\mathrm{X}$, Day RS, Hassan MM, Li D.(2010). Antioxidant genes, diabetes and dietary antioxidants in association with risk of pancreatic cancer. Carcinogenesis , 31: 607-613.

Tsukuma H, Hiyama T, Tanaka S, (1993).Risk factors for Hepatocellular carcinoma among patients with chronic liver disease. N Engl J Med , 328: 1797-1801.

Zheikova TV, Golubenko MV, Buikin SV, Yu BO, Makeeva OA, Lezhnev AA, Kalyanov EV,
Tsimbalyuk IV, Maksimov VN, Voevoda MI, Shipulin VM, Puzyrev VP.(2012).. Glutathione Peroxidase 1 (GPX1) Single Nucleotide Polymorphism Pro198 $\rightarrow$ Leu: Association with Life Span and Coronary Artery Disease. Molecular Biology , 46: 433-437

Zhou L, Yang Y, Tian D, Wang Y.(2013). Oxidative stressinduced 1, N6-ethenodeoxyadenosine adduct formation contributes to hepatocarcinogenesis. Oncol Rep , 29(3): 875-884. 